\title{
Developing Mobile Tracking Applications for Patient Treatment
}

\author{
Hussain Mohammad Abu-Dalbouh ${ }^{1}$ \\ ${ }^{1}$ College of Sciences and Arts at Unaizah, Computer Science Department, Qassim University, Al-Qassim, \\ Kingdom of Saudi Arabia \\ Correspondence: Hussain Mohammad Abu-Dalbouh, College of Sciences and Arts at Unaizah, Computer Sciences \\ Department, Qassim University, Al-Qassim, Kingdom of Saudi Arabia. E-mail: hussainmdalbouh@yahoo.com
}

Received: Oct. 7, 2018

doi:10.5539/cis. v12n1p12
Accepted: Nov. 1, 2018

Online Published: January 18, 2019

URL: https://doi.org/10.5539/cis.v12n1p12

\begin{abstract}
Much of the adjunct technology developed for using among medical environments is targeted towards computers. Because the hospitals face increasing demands to participate in a very big selection of quality improvement activities, the role and influence of using mobile applications in these efforts is additionally increasing. The professionals of Healthcare pay abundant of their time wandering between offices and patients, whereas the validator technology stays stationary. This paper presents a study performed using the mobile application for storing and following up patients status. Therefore, mobile application for tracking patient progress is proposed to minimize such challenges and demands, by allowing physicians and nurses to trace the patients' conditions a lot of expeditiously and simply. The experimental results conclude that the working environment would be improved by supporting the mobile workers with mobile technology.
\end{abstract}

Keywords: mobile, tracking system, healthcare, system, patient, technology, system

\section{Introduction}

According to Gover and Huray (2000) recently, the medical technology has developed. This has the foremost engine to diagnose and treat many human diseases. Therefore reduced mortality and morbidity for millions folks. The costs of medical paid by the governments grow so quickly that it will be necessary to reduce different areas of country disbursement. Technology plays a significant role in each field of contemporary development and is a necessary tool in health care.

Abu-Dalbouh (2013) said that mobile technology and handhelds have offered a chance to produce a brand new generation of individuals with suggests that to move with activities regardless of location. On the whole, AbuDalbouh $(2014 a, 2014 b)$ examined that probability the quick advancement of handheld gadget and versatile correspondence, business exercises will split far from the constraint of the locale and time well ordered that expedite the proceeding with impacts associations. (Lihua, 2005). Mobile computing applications permit anytime, anyplace access to the web and company intranets.

The specializes in diagnosis and medical treatment/physicians at differed doctor's facilities confront numerous issues with pursue the patient's standing, where in typical case specialist still relies upon paper to record and track the patient's standing advancement, at intervals the decision words pursue has been finished by manual way. This causes harms, lost and loss of a few papers with respect to data of the patients. To boot, attendants and doctors need to check the patient standing day by day and provide details regarding the advancement of the patient. Along these lines this constrained the doctors to follow every one of the patients and peruse their reports. Pursue physically is mulled over wasteful and time overpowering. This some patient's standing is given by the reports while not the requirement for the doctors checking. A few requests square measure commonly given to medical attendants to accomplish the errand and numerous cases can't look forward to the doctors checking round. Also, patients don't appear to be in many cases given composed information concerning their consideration and treatment, making it great for specialists and medical attendants to recall and deal with their consideration successfully. To relieve the previously mentioned issues this examination expected to build up a handheld goals that may bolster healing facilities in pursue patients advance and defeats these troublesome.

\section{Literature Review}

Doctors should analyze related to utilize a development of medicines to patients. Though not up their instrumentation and innovation, they will confront an enormous test. In this manner, human services executives 
relate constantly scanning for the preeminent ongoing advancements which may enhance the yield. In clinic framework, one refined issue can hinder the point, in making an endeavor to remain track of what's happening all through the medicinal services framework with every patient. Their requests, lab, radiology, and absolutely totally unique appropriate outcomes, and even broad data like medical caretakers allotted to them on a particular move an important to remain the stream of consideration. Deferring this stream will devour time of the procedure of their consideration. Subsequently on face the time utilization, code firms relate constantly hunting down better than ever manners by which all through which to enable wellbeing to mind providers in higher overseeing work force and time span (Abu-Dalbouh (2016a, 2016b).

\subsection{Mobile Application}

Nowadays, with the expanding development in innovations, cell phones being utilized in a few fields like farming, medicinal, after and learning. Cell phones turned out to be wide utilized innovation. The most point is to change correspondence and information get to wherever and whenever (Fogg, 1999). Moveable device is incidental users most of the time. Thus, makes it a motivating platform for building convenient applications which will show output any half within the world (Ichikawa, Chipchase and Grignani, 2005). Mobile devices a used normally in existence to speak, coordinate and to access data. Additionally (Abu-Dalbouh, 2013) attention professionals pay abundant of their time wandering between patients and offices, whereas the supportive technology stays stationary. Therefore, mobile applications has custom-made for attention business.

\subsection{Mobile Application in Health Care Area}

For the majority of handheld technique for creating medicinal services, handheld firms got the opportunity to style and supply a framework that is valuable and basic access the learning in social insurance databases. Besides, inside the truth the phones began abuse PCs (applications like PDA) to encourage shared criticism on the medicinal services setting viability like clinical aptitudes examination, bolster ceaseless quality change activity, give treatment and watching administrations. In accordance with Suomi (2003) wellbeing proficient is contestation to utilize PCs and versatile applications with exchanges through the web. The patients put weight on human services providers like reached through telephone or by means of the web.
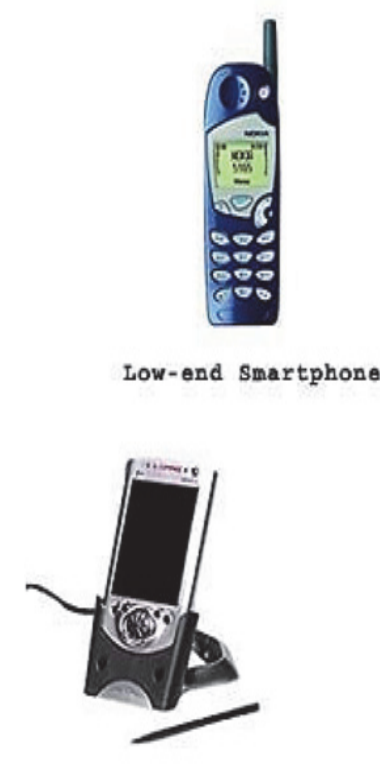

PDA

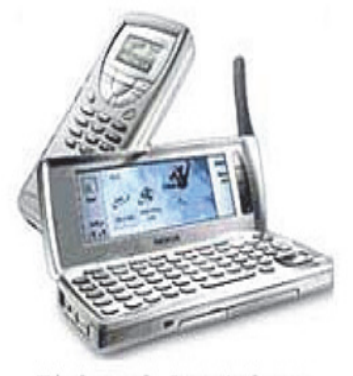

H1gh-end Smartphone

Figure 1. The new generation of mobile phone

\subsection{Handhelds in Health Care}

In view of $\mathrm{Lu}$ et al (2005) versatile gadgets have turned out to be very much preferred in restorative practices, it is most blazing because of it prepared to store a gigantic measures of information inside the pocket. A portable customer grants remote access to reference material, clinical working environment information and patient wellbeing states by means of a remote connection. (Berglund et al., 2007) Have shown an investigation at a Swedish area healing center wherever specialists and medical attendants has high uplifting desires for utilizing 
handheld emotionally supportive networks. An examination was directed of meetings that demonstrated that doctors would a versatile device for getting to such information concerning patients, an information and capacities to ease and institutionalize regular assignments. It additionally, has the adaptability to get a handle on the patient's status. Rapidly for a patient's condition. In this way, there is required for portable access to the database and data. The examination together demonstrated that the medical attendants unit concerned concerning subtle with the connection between the workers and patient. The apparatus got the opportunity to be clear to utilize, therefore the treating workers center can be the patient and to not the non-open Computerized encourage (PDA). The specialists and medical attendants express that entrance to inspect results and reference esteems has the best need once needing in patient data.

In (Fischer et al., 2003) it is pronounced that the most assets to help therapeutic work would be versatile available. Fundamentally, inside the treatment information databases, following patient wellbeing, value following and remedy of physician endorsed drugs. (Lu et al., 2005; Fischer et al., 2003) has each led investigation projects to supply survey articles close by held registering used in restorative conditions up till 2004. The most supply for every article is telephone framework and distinctive restorative reference libraries. The examinations don't talk about additions in quality or coordinated effort to the degree that may be found in Human Computer Interaction ( $\mathrm{HCI})$, Computer Supported Cooperative Work (CSCW) or portable data science investigation fields. The articles assessed were in the fundamental focused on the sensible utilization of portable medicinal applications. Quality and correspondence region unit specified the upsides of the recovery and utilization of patient and restorative information territory unit the most subject. Getting to therapeutic information wherever and once required is that the normal divisor which may make hand-held gadgets an important commitment to restorative work.

\subsection{Mobility Health Care}

$\mathrm{Lu}$ et al (2005) said that utilizing portable application in medicinal services division is enchained that a great deal of value would enhance quiet mind and allow healing facility work force to pay longer with patients and decreased the season of social event information. The handheld gadget would give the client a considerable measure of opportunity to orchestrate and pay their chance. The uncommon limitations required by stationary information arrange powers the client into an example wherever a "command post" must be visited at interval to amass information for present and extra work exercises. A versatile answer helps the client by giving up to now information on any area, and conjointly allowing a considerable measure of familiar time plan wherever essential occasions is seen and followed up on. (Luff, Heath and Singh, 1998Have discovered that members in investigations of fluctuated settings have confidence in their own quality and furthermore the nature of ancient rarities to be prepared to facilitate exercises with others. In their investigation of the presentation of PC based for the most part records into the restorative interview they investigated anyway the innovation has undermined coordinated effort. Antiquated paper records bolster coordinated effort between every clinician and elective experts, and among patient and furthermore the professional. Luff and Heath all out that paper records work a vital asset for correspondence and coordinated effort and territory unit, even with the presentation of prepared frameworks, an imperative asset in gifted practice. The paper winds up fundamental because of it is convey ability; it is passed around, be conveyed, and be influenced between totally extraordinary components of an area. It is same that once creating versatile advances to help cooperation between clients, engineers got the chance to investigate in extra detail anyway protests zone unit used in associations wherever quality is urgent.

(Lundberg and Sandahl, 1999) Stressed the importance of artefacts in a surroundings wherever written paper features a price itself. A paper act as a token and also the shelf acts as a live of the employment. Actions like moving a document from one table to a different, face-to-face discussions and the utilization of boards for programming influences totally different quite reciprocity in medical work. In another article (Lundberg and Tellioglu, 1999) concludes that translating the coordinating role of paper documents and alternative coupled artefacts to pc systems could be a challenge as a result of artefacts a part of a shared infrastructure and desires to be higher understood. Lundberg and Tellioglu explained that system designers have to be compelled to perceive the advanced coordination of labor in a corporation so as to support coordination. An angle towards artefacts should be thought-about once presenting information on a handheld device rather than the binders used nowadays. The impact of exploitation handheld devices in medical work instead of stationary computers would be high, the traditional modes of operational in a hospital surroundings is by wandering between totally different locations of labor (Kristoffersen and Ljungberg,1998) Adding frequent derails to the present work flow for visiting a stationary pc would be to attenuate the impact, particularly if an issue can't be answered whereas being with a patient and also the practitioner has to leave to search out the answers for that question. For the bulk of mobile device strategy for developing attention. Abu-Dalbouh and Almueit (2013) have designed and provided a system that is useful and simple access the data in health care databases. Additionally for pursuit in patient progress in hospital. 
Abu-Dalbouh (2014) planned a mobile health model that would support hospitals in pursuit patient's progress and improve the standard care in hospitals. It permits physicians and nurses to trace the patients' conditions additional expeditiously and simply. It conjointly ready to assist in crucial clinical selections $24 / 7$ and out there on decision where physicians to manage their care method from begin to end and from within and out of doors the hospital.

\section{Proposed System Design}

The proposed system is designed and implemented to review the gaining of the proposed mobile model that has been planned and to check the efficiency of introducing mobility to patient tracking. The end-users of the proposed system are Doctor and Nurse.

The functionality of a system as Doctor Actor: The doctor should press to login the system as a Doctor, then the Doctor should enter the patient ID to use the system.

The functions for doctor actor: View Patient Information, Manage Patient Progress, View Patient State, Enter Patient State and View Patient History. While the functions for Nurse Actor: The nurse should press to login the system as a Nurse, then the Nurse should enter the patient ID to use the system. Then the Nurse should enter the patient ID to use the system to use the system. The functions for Nurse Actor: View Patient Information and View Patient State. Figure 2 shows the functionality of both actors.

\section{MOBILE TRACKING ON \\ PATIENT PROGRESS (m-TOPP)}

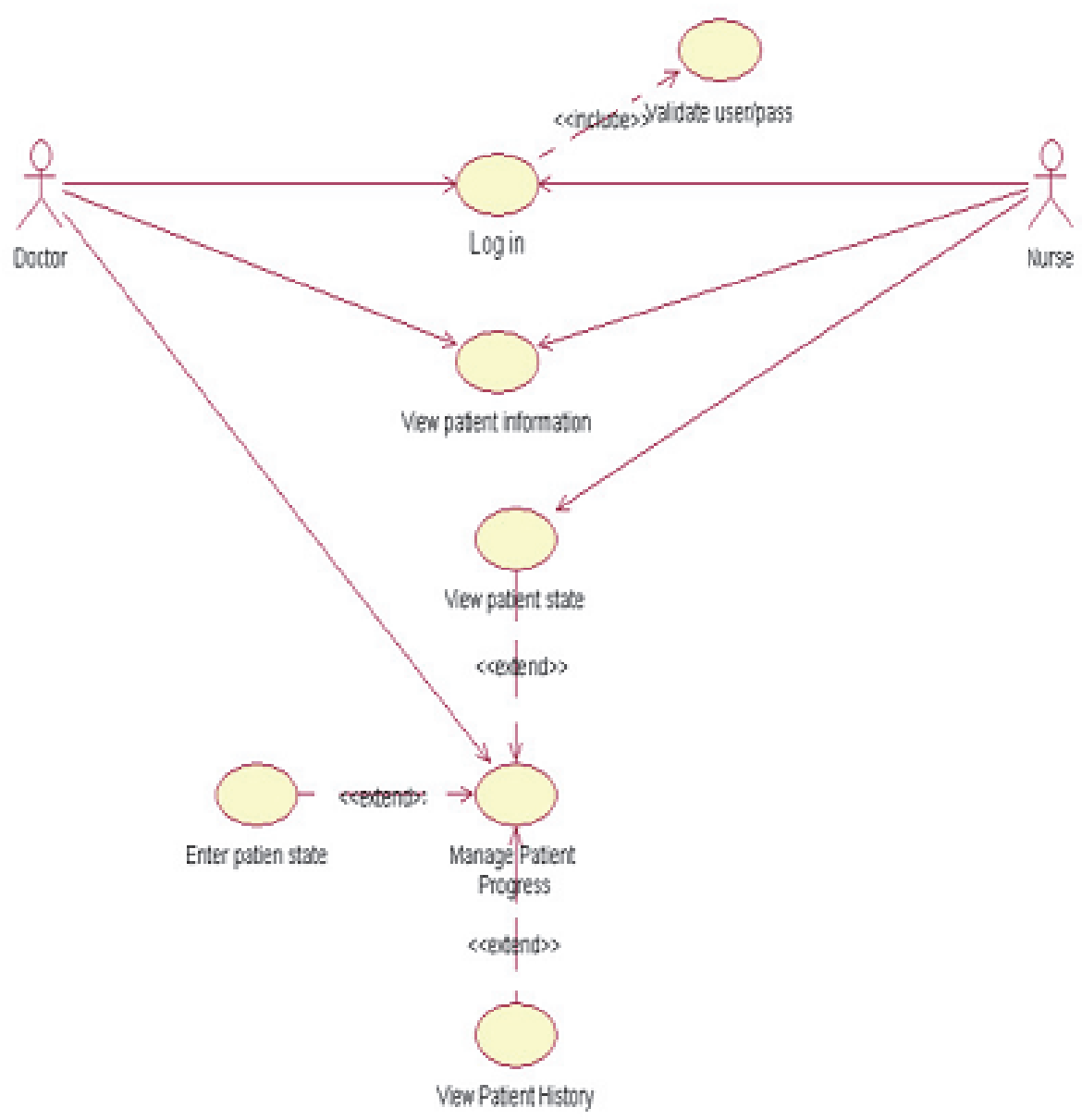

Figure 2. Main Use Case for m-TOPP system

The following snapshots explain the m-TOPP system. 


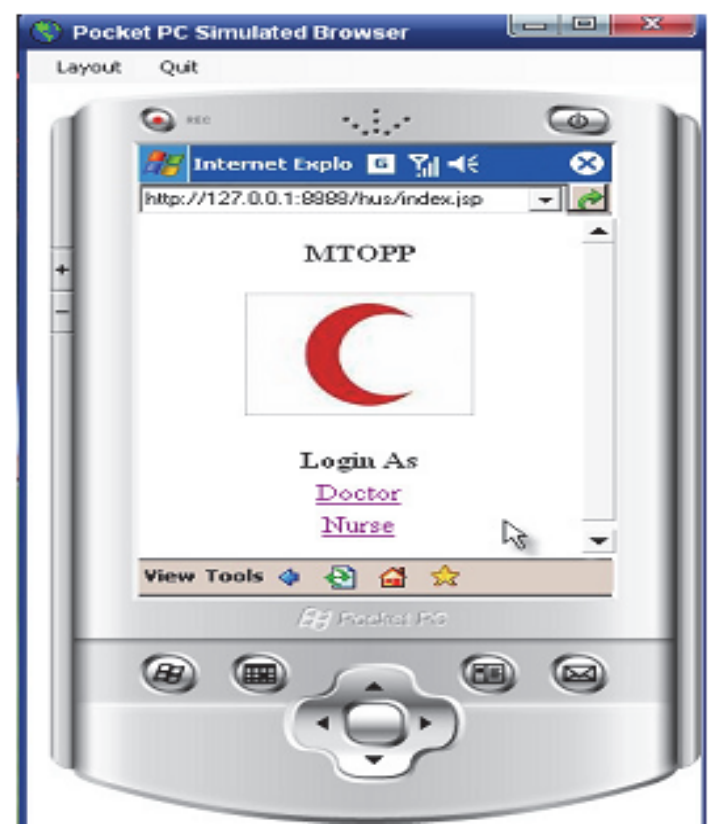

Figure 3. Main page

The main page displays the title of the system and two types of logging (Login for doctor and login for nurse).

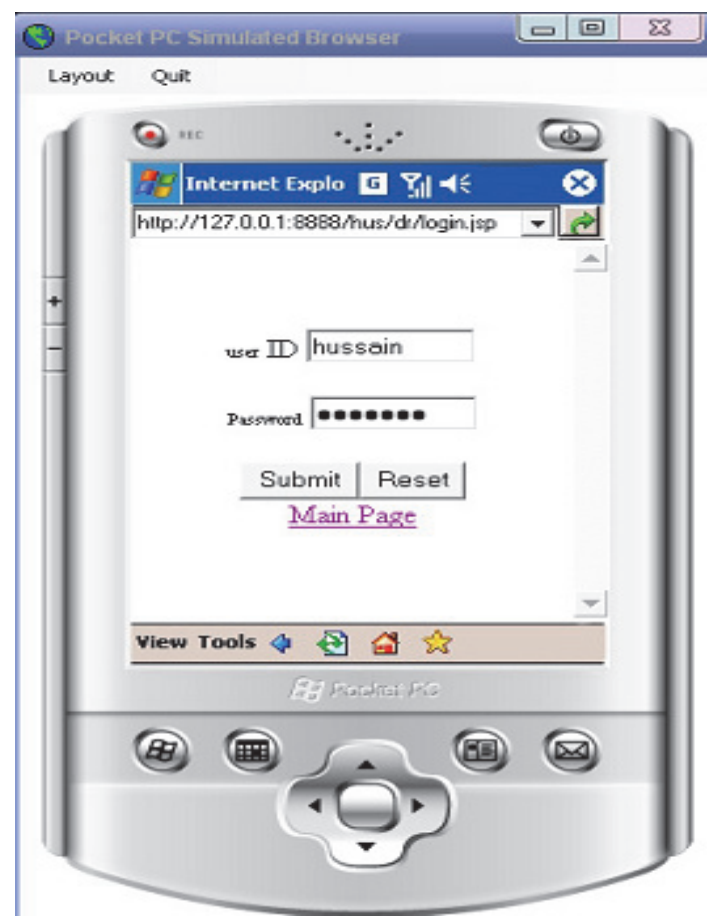

Figure 4. Log in page

After pressing the doctor button in the main page, the prototype displays a page to enter a user ID and password 


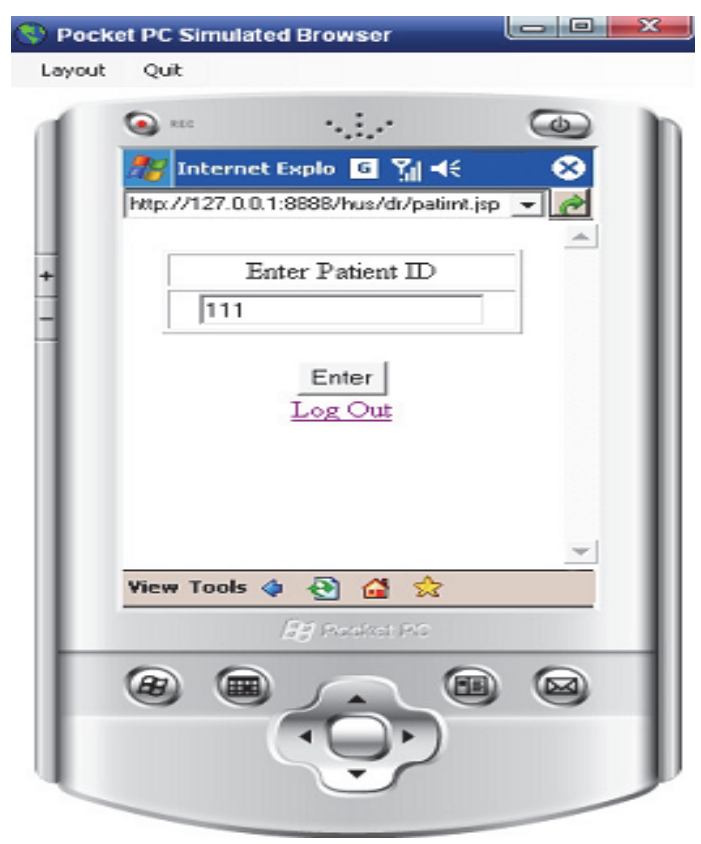

Figure 5. Patient ID page

Entering Patient ID by the doctor to view patient information and manage patient progress.

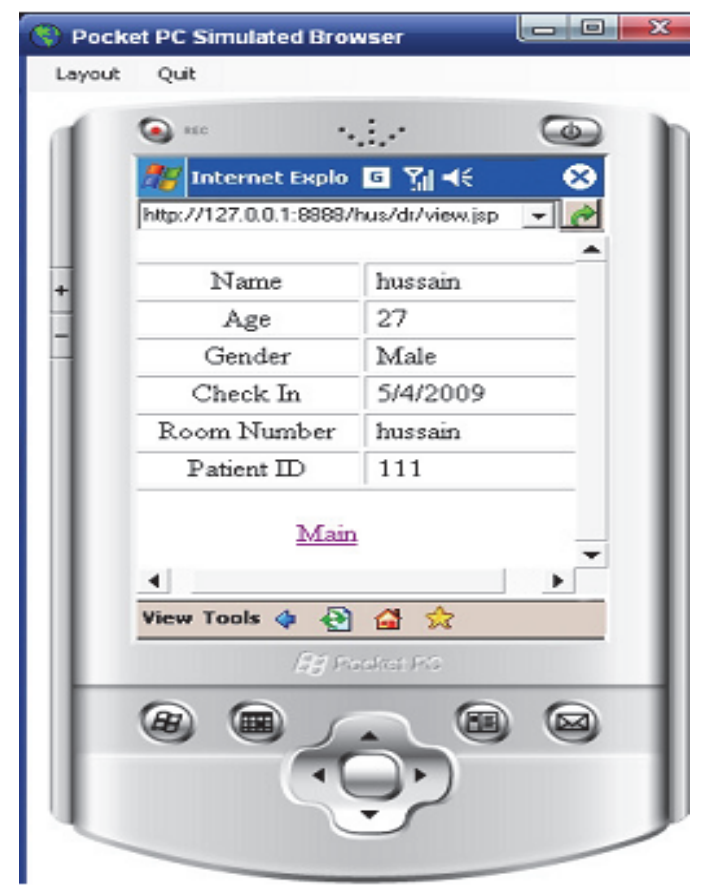

Figure 6. Patient profile

Figure 6 shows that the doctor can see the patient profile such as name, age, gender, check in, room number and patient ID. 


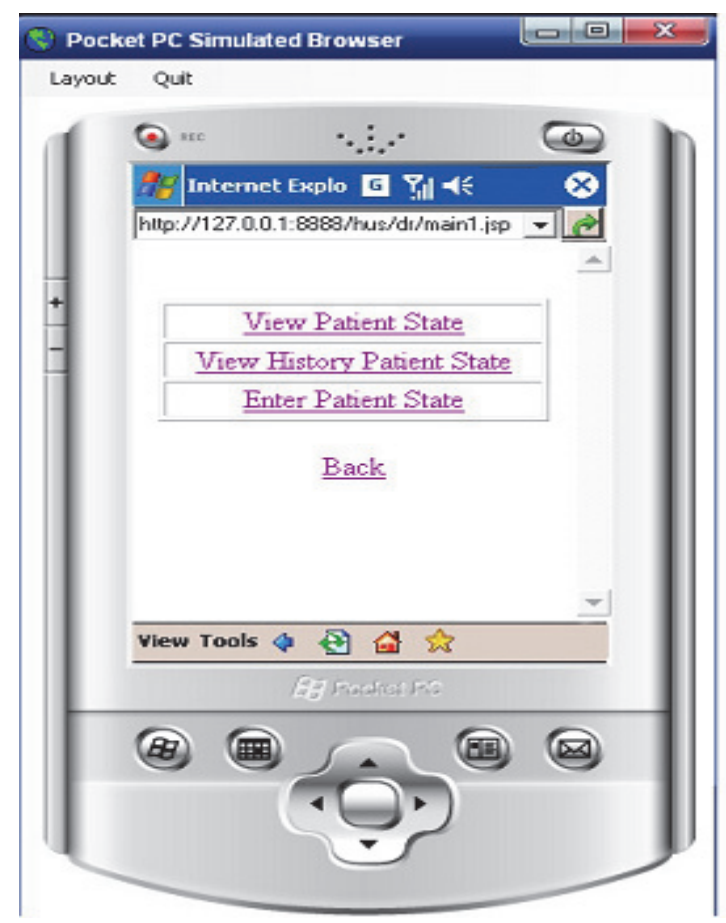

Figure 7. Managing patient progress page

For managing patient progress page, it contains three buttons: view patient state, view history patient state and enter the patient state.

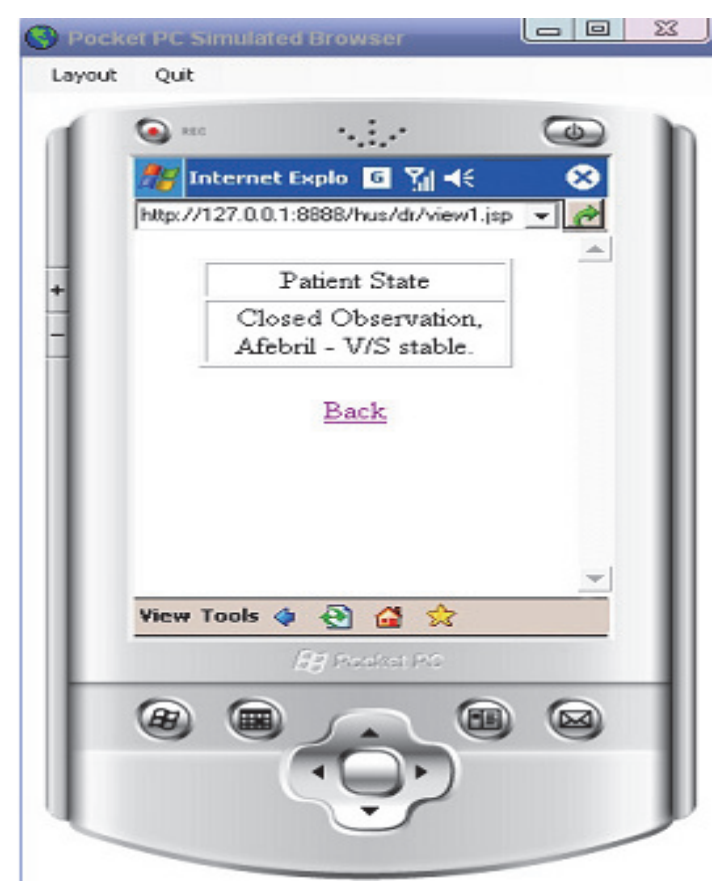

Figure 8. View patient state

View patient state enables the doctor to see the latest patient condition (state) that recorded in the patient file. 

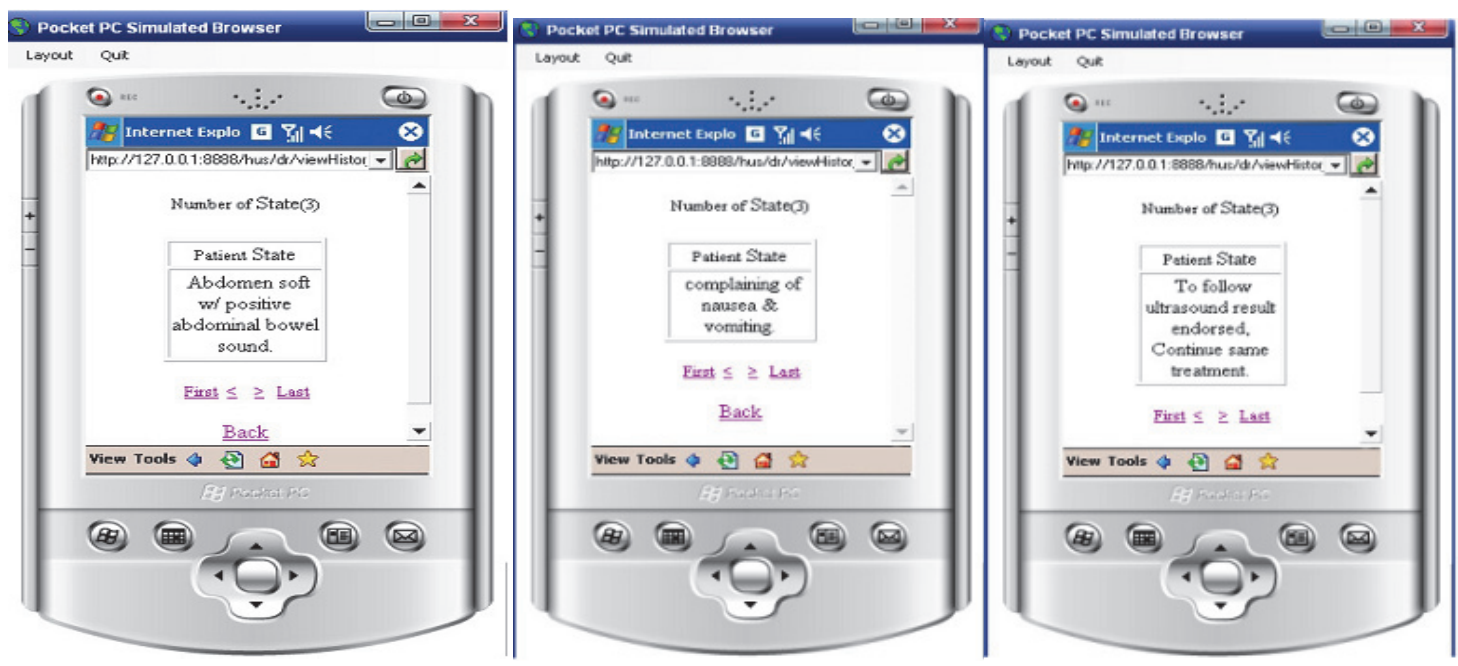

Figure 9. Patient history

View history patient state enables the doctor to see all patient conditions (state) that was recorded in the patient file. It shows the three patient states, the doctor can check these entered states using first and last buttons.

\section{Result and Discussion}

In the user experiments of the m-TOPP system, we asked 30 responders ( 8 doctors and 22 nurses) to use and discover the m-TOPP system for several minutes and evaluate it.

All the responders were Doctors and Nurses belonging to the targeted hospital, the scope of this study. All variables were measured using 5- points Likert scale (Strongly Disagree, Disagree, Natural, Agree and Strongly Agree). From the study, the descriptive statistics for the highest items in Table 1. The charts below detail of these 3 highest items.

Table 1. Top 3 Highest Items

\begin{tabular}{lcc}
\hline \multicolumn{1}{c}{ ITEMS } & MEAN & ST.DEV \\
\hline m-TOPP system allows the doctor to follow up the patient state from & 4.033 & 0.8087 \\
outside of the hospital & & \\
It is easy to become skilful of using m-TOPP system & 3.97 & 0.900 \\
It is easy to interact with m-TOPP system by using a mobile phone & 3.97 & 0.89 \\
\hline
\end{tabular}

The system allows the doctor to follow up the patient state from outside of the hospital

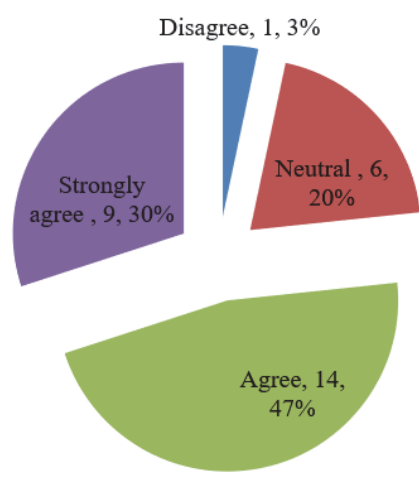

Figure 10. Item 1 statistic 
It is easy to become skilful of using this system

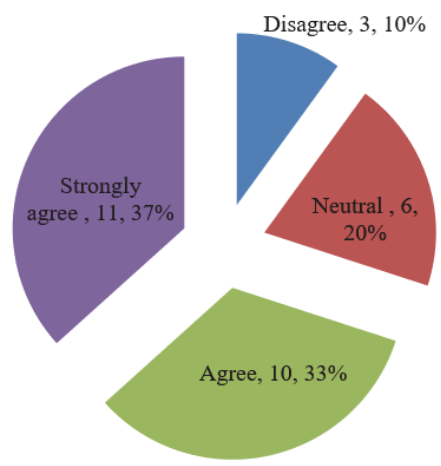

Figure 11. Item 2 statistic

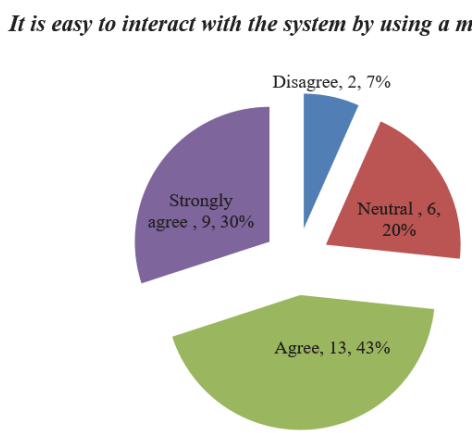

Figure 12. Item 3 statistic

The descriptive statistics for the main variables in Table 2 and Figure 5 revealed that all dimensions charted higher than the midpoints of their respective scales. It shows that respondents are generally optimistic about the Perceived Usefulness (PU) and Ease of Use (PEU) about using the $\mathrm{m}$ - TOPP system.

Table 2. Descriptive for the main variables

\begin{tabular}{llll}
\hline Variable & MEAN & \multicolumn{2}{c}{ ST.DEV } \\
\hline Perceived of Usefulness & 3.92575 & 0.849925 \\
Perceived ease of Use & 3.8825 & 0.945 \\
User Satisfaction & 3.756667 & 1.078667 \\
Attribute of Usability & 3.813333 & 0.989667 \\
\hline
\end{tabular}
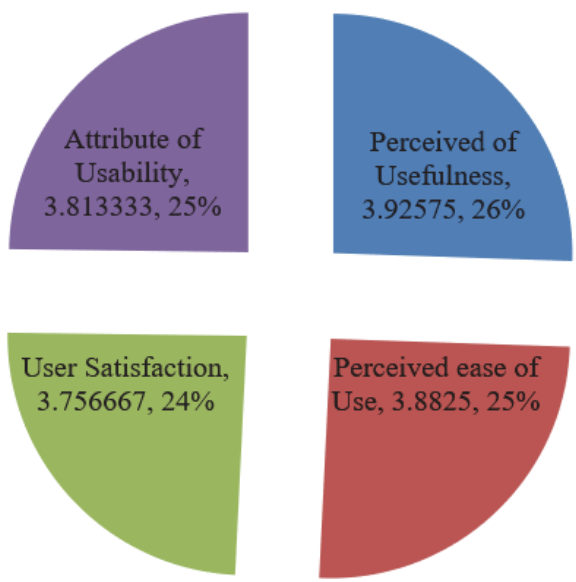

Figure 13. Descriptive for the main variables 
Both Expert users agreed for the contribution of the m-TOPP in the healthcare sector and the answers were satisfactory. They found that the m-TOPP system is:

- Easy to use

- Language is clear

- Interaction is clear and understandable

- Useful in the rapid retrieval of information

- Save the time

- Overcome the loss or damage of some patient information

- Applicable and efficient

The respondents and the expert users proved that the m-TOPP system allows the doctor to follow up the patient state from outside of the hospital, enable the doctor and nurse to get the information of the patient quickly and will save the time of doctor and nurse. Additionally, it is useful for rapid retrieval of information about the patients. Therefore, based on the results of this evaluation, the m-TOPP system shows promise as a tool and a highly effective modality for tracking the patient condition more efficiently and easily and overcomes the damages, misplaced and loss of some papers relating to information of the patients by using mobile model.

\section{Conclusion}

During recent years, weight on rising the standard of consideration given by the doctor's facilities has expanded impressively and keeps on accomplishing energy. because of specialists and medical attendants are fundamental to hospitalized following patient's advancement and polar in healing facility endeavors to upgrade quality, Thusly, the interest currently is making new should encourage and make higher choices as utilizing the versatile application heading the correct way patient's advancement. Along these lines, anticipated versatile after on the patient advancement framework is presented amid this paper. By consolidating versatile after on Patient Advancement the specialist will catch up the instance of the patient from outside the healing center's to enter the framework worldview and noticed the amount of change bolstered reports keep. It likewise, specialists and medical caretakers will track the condition of patient a considerable measure of speedily. The proposed framework it is basic for the specialists and medical attendants to share information concerning condition of patients. Doctor ready to assist in crucial clinical selections $24 / 7$ and offered on decision where doctors to manage their care method from begin to end and from within and outdoors the hospital. Therefore this study is developed a handheld solution that could support hospitals in tracking patient's progress. In the hospital where this study was conducted the doctors and nurses face problems to track the patients state and share the information of the patients. By using the proposed system the doctors can enter patient state, view patient state, view patient history and view patient information. It also allow nurses to view patient information and view patient state. It enables the doctors and nurses to take data and information of patient through mobile application such as personal digital assistance (PDAs).

\section{References}

Abu-Dalbouh, H. (2014a). A Proposed mHealth Model for Improving the Quality Care in Hospitals. Research Journal of Applied Sciences, Engineering and Technology, 7(7), 1215-1219. February 2014. Retrieved from http://maxwellsci.com/print/rjaset/v7-1401-1405.pdf

Abu-Dalbouh, H. (2014b). m-TOPP-UML: An Extension to UML for the Modeling of Mobile Tracking on Patient Progress System. Research Journal of Applied Sciences, Engineering and Technology, 7(7), 1202-1208. February 2014. Retrieved from http://maxwellsci.com/print/rjaset/v7-1388-1394.pdf

Abu-Dalbouh, H. (2016a). An Integrated Expert User with End User in Technology Acceptance Model for Actual Evaluation. Computer and Information Science, 9(1), 47-53. https://doi.org/10.5539/cis.v9n1p47

Abu-Dalbouh, H. (2016b). Using a Modified Technology Acceptance Model to Evaluate Designing Eight Queens Chess Puzzle Game. Journal of Computer Science. J. Comput. Sci., 12(5), 232-240. June 2016. https://doi.org/10.3844/jcssp.2016.232.240

Abu-Dalbouh, H. M. (2013). A questionnaire approach based on the technology acceptance model for mobile tracking on patient progress applications. J. Comput. Sci., 9(6), 763-770. https://doi.org/10.3844/jessp.2013.763.770

Abu-Dalbouh, H., \& Almueit, M. Z. (2013). Designing Mobile Tracking Solution in Monitoring Patients. ICIT 2013 the 6th International Conference on Information Technology. May 2013. Conference. (2, pp.1346-1350).

Berglund, M., Nilsson, C., Révay, P., Petersson, G., \& Nilsson, G. (2007). Nurses' and nurse students' demands of functions and usability in a PDA. International Journal of Medical Informatics, 76, 530-537. 
Fischer, S., Stewart, T. E., Mehta, S., Wax, R., \& Lapinsky, S. E. (2003). Handheld Computing in Medicine. Journal of American Medical Informatics Association, 10(2).

Fogg, B. J. (1999). Persuasive Technologies. Communications of the ACM, 42(5), 27-29.

Gover, J., \& Huray, P. G. (2000) The engineer's role in averting the pending health care cost crisis. Albuquerque, NM, pp. 687-691.

Ichikawa, F., Chipchase, J., \& Grignani, R. (2005). Where's the Phone? A Study of Mobile Phone Location in Public Spaces. In Proc. IEEE Mobility Conference 2005 in Guangzhou, China, pp. 797-804.

Kristoffersent, S., \& Ljungberg, F. (1998). Representing Modalities in Mobile Computing. In Proceeding of Interactive Applications of Mobile Computing, (IMC'98).

Lihua, C. Y. (2005) Mobile business applications adoption model based on the concepts of task/technology fit. Services Systems and Services Management, 2005. Proceedings of ICSSSM '05. 2005 International

Lu, Y. C., Xiao, Y., Sears, A., \& Jacko, J. A. (2005). A review and a framework of handheld computer adoption in healthcare. International Journal of Medical Informatics, 76, 409-422.

Luff, P., \& Heath, C. S. (1998). Mobility in collaboration. Proceedings of the 1998 ACM conference on Computer supported cooperative work, pp. 305-314.

Lundberg, N., \& Sandahl, T. (1999). What do Artifacts Mean to us in Work? Proceedings of the 22th IRIS, pp. 363-372.

Lundberg, N., \& Tellioglu, H. (1999). Understanding complex coordination processes in health care. Scandinavian Journal of Information Prototypes, 11(2), 157-181.

Suomi, R (2003) Establishing a contact center for public health care. Proceedings of the 36th Hawaii International Conference on System Sciences, p. 10.

\section{Copyrights}

Copyright for this article is retained by the author(s), with first publication rights granted to the journal.

This is an open-access article distributed under the terms and conditions of the Creative Commons Attribution license (http://creativecommons.org/licenses/by/4.0/). 